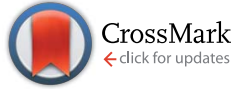

Cite this: Soft Matter, 2015, 11, 1945

\title{
Differential response of cholesterol based pyrimidine systems with oxyethylene type spacers to gelation and mesogen formation in the presence of alkali metal ions $\dagger$
}

\begin{abstract}
Sougata Datta ${ }^{a}$ and Santanu Bhattacharya*abc
A new series of lipophilic cholesteryl derivatives of 2,4,6-trichloro-pyrimidine-5-carbaldehyde has been synthesized. Oxyethylene spacers of variable lengths were inserted between the hydrogen bonding promoting pyrimidine core and the cholesteryl tail in order to understand their effect on the selfassembly of these compounds. Only compound 1a with the shortest spacer formed a gel in organic solvents such as $n$-butanol and $n$-dodecane. While other members ( $1 b$ and $c$ ) having longer spacers led to sol formation and precipitation in $n$-butanol and $n$-dodecane respectively. The self-assembly phenomena associated with the gelation process were investigated using temperature-dependent UVVis and CD-spectroscopy. The morphological features of the freeze-dried gels obtained from different organic solvents were examined by scanning electron microscopy (SEM) and atomic force microscopy (AFM). The solid phase behaviours of these molecules and their associated alkali metal ion complexes were explored using polarized optical microscopy (POM) and differential scanning calorimetry (DSC). The molecular arrangements in the xerogel and in the solid state were further probed using a wide-angle $X$ ray diffraction (WAXD) technique. Analysis of the wide-angle $X$-ray diffraction data reveals that this class of molecules adopts a hexagonal columnar organization in the gel and in the solid state. Each slice of these hexagonal columnar structures is composed of a dimeric molecular-assembly as a building block. Significant changes in the conformation of the oxyethylene chains could be triggered via the coordination of selected alkali metal ions. This led to the production of interesting metal ion promoted mesogenic behaviour.
\end{abstract}

Received 16th December 2014 Accepted 13th January 2015

DOI: $10.1039 / c 4 s m 02792 b$

www.rsc.org/softmatter gelators $^{\mathbf{2 , 8 , 1 4 - 1 7}}$ comprising certain low-molecular weight molecules are particularly useful because of their anisotropic properties in contrast to their solution and crystal states. In addition, self-assemblies of the low molecular-weight organogelators (LMOGs) are thermo-reversible in most of the cases, i.e., they show reversible sol-to-gel transitions when their heated solutions are cooled below the respective gelation temperatures. ${ }^{2,8,14-21}$

Low molecular-weight organogelators (LMOGs) (2, 14-22 $^{\text {and }}$ liquid-crystals (LCs $)^{23-25}$ are the topics of growing attention because of their numerous potential applications. They have been recognized as high technology materials because of their diverse utility in various fields, including the design and synthesis of nanomaterials, ${ }^{26,27}$ biomaterials, ${ }^{28}$ sensors, ${ }^{29-32}$ stimuli-responsive materials ${ }^{33,34}$ and in molecular electronics ${ }^{35-37}$ and catalysis. ${ }^{38,39}$ In addition to their self-organizing potential in the solid/gel or solution state, additional properties such as luminescence, ${ }^{40}$ redox activity, ${ }^{41}$ sensing, ${ }^{42}$ self-healing, ${ }^{43}$ etc. may be induced by incorporating metal ions inside the pre-designed building blocks, leading to functional or multifunctional materials. ${ }^{\mathbf{4 4}}$

\footnotetext{
${ }^{a}$ Department of Organic Chemistry, Indian Institute of Science, Bangalore 560012 +91-80-22932664

${ }^{b} J a w a h a r l a l$ Nehru Centre for Advanced Scientific Research, Jakkur, Bangalore 560 064, India

'J. C. Bose Fellow, Department of Science and Technology, New Delhi, India $\dagger$ Electronic supplementary information (ESI) available: Complete synthetic procedures, compound characterization data for the cholesteryl derivatives described in the text, UV-Vis spectra, DSC profiles and wide-angle X-ray diffraction data. See DOI: 10.1039/c4sm02792b
} 
Various types of organic molecules are used in recent years to achieve gelation involving non-covalent interactions as the driving force. Strong and directional hydrogen bonding interactions are the main driving force for amide, ${ }^{45-49}$ urethane, ${ }^{50}$ urea ${ }^{51}$ and sugar derived gelators. ${ }^{52-55}$ However, van der Waals force is often the dominant interaction among the steroid derivatives. ${ }^{56}$ Cholesteryl derivatives have been exploited as versatile soft materials, some of which exhibit bilayer membrane forming properties, chiral recognition, organogelation and liquid-crystalline behaviour depending upon the self-assembly process. ${ }^{57-61}$ These properties generally originate due to the presence of the cholesterol backbone in these molecules. In one of the earlier reports, Weiss and co-workers explored the structure and property relationships of various aromatic group appended cholesterol-based gelators. ${ }^{62}$ Shinkai's group demonstrated the formation of helical supramolecular aggregates by azobenzene appended cholesterol-derived gelators. ${ }^{63}$ The same authors have also shown remarkable stabilization of crown-based organogels in the presence of a bipyridinium-based guest by the synergistic effect of H-bonding, hydrophobic and charge-transfer interactions. ${ }^{64}$ Cholesteryl derivatives bearing a crown ether or azobenzene moiety were shown to display the unique characteristics of cholesteric liquid-crystals and organogelation by photo-irradiation or via crown ether-metal ion interactions. ${ }^{6-67}$ Jung and co-workers showed significant stabilization of asymmetric bolaamphiphilic sugar-based hydrogelators in the presence of alkyl diammonium ions as guests by the synergistic effect of $\mathrm{H}$-bonds. ${ }^{68}$ Qi et al. synthesized and investigated achiral benzo-21-crown-7substituted bis-urea LMOGs which hierarchically assembled into helical fibrils and further developed into bundles and finally formed a stable gel in acetonitrile. The gel-sol transition could be modulated by $\mathrm{K}^{+}$ion binding to the crown ethers, pseudorotaxane formation with secondary ammonium ions and chloride anion binding with the urea units. ${ }^{69}$

Several non-covalent and non-classical approaches have been adopted for the production of liquid-crystalline materials. ${ }^{5,6,70-73}$ Metallo-mesogens are among the best examples for the fabrication of a variety of materials. These systems not only contain different metal species, but also exhibit a variety of phases. $^{70-72,74}$ Previously, luminescence properties were introduced by the grafting of organic luminophores, exhibiting optical properties, ${ }^{75-77}$ or by the anchorage of platinum complexes, as triplet emitters. ${ }^{78}$ Various chelating agents were also integrated on the platforms such as polypyridine fragments or crown ethers leading to functional metallo-mesogens after metal ion coordination. ${ }^{79,80}$ Similar to stimuli-responsive gels, ${ }^{81}$ ion-responsive liquid crystals of organic molecules are of recent interest because of their switching to different liquid-crystalline structures which result in interesting properties. ${ }^{82-85}$

It has been demonstrated that the monoesters of triethylene glycol with 3,4,5-tris( $n$-dodecan-1-yloxy)-benzoic acid are crystalline solids. Complexation with the $\mathrm{Li}^{+}$ion, however, destabilizes their crystalline phase and drives the same to selfassemble into a cylindrical architecture which finally results in a hexagonal columnar mesophase..$^{82}$ A similar observation was obtained on addition of sodium triflate to the crown ether receptor of benzo-15-crown-5 benzoate $[6,7,9,10,12,13,15,16$ octahydro-1,4,7,10,13-pentaoxa-benzocyclopentadecen-2-ylmethyl3,4,5-tris( $p$-dodecyloxybenzyloxy)benzoate]. ${ }^{83}$ Kato and co-workers reported a triphenylphosphine oxide (TPPO) compound bearing 3,4,5-tridodecyloxybenzyloxy moieties, capable of exhibiting a columnar liquid-crystalline phase. ${ }^{84}$ Interestingly, complexation with the $\mathrm{Li}^{+}$ion stabilized the columnar phases due to the iondipole interaction, whereas a cubic phase was observed in the presence of the $\mathrm{Na}^{+}$ion. Kohmoto's group explored triphenylene derivatives with oxyethylenes as side-chains exhibiting a unique alkali metal ion induced discotic nematic $\left(\mathrm{N}_{\mathrm{D}}\right)$ to hexagonal columnar $\left(\mathrm{Col}_{\mathrm{h}}\right)$ phase transformation. ${ }^{85}$ There are other instances of utilization of oligo-(oxyethylene) units as a spacer in the modulation of properties of various supramolecular and biologically active systems as well. ${ }^{86-90}$

Fenniri introduced an interesting molecular scaffold based on 4-chloro-2,6-bis(octadecylamino)pyrimidine-5-carbaldehyde, which is capable of generating fibrous lamellar structures in both dry solid and gel states. ${ }^{91}$ Subsequently, we have developed a family of organogelators based on L-amino acid

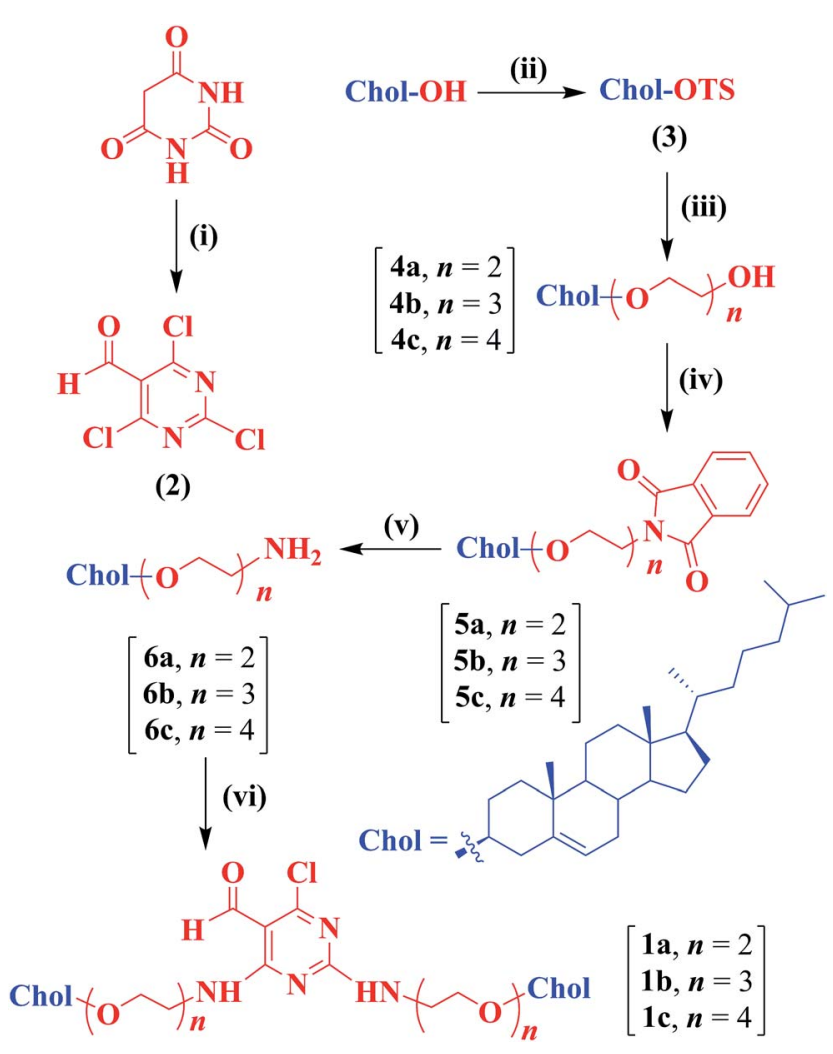

Scheme 1 Synthetic scheme of cholesteryl derivatives of 2,4,6-trichloro-pyrimidine-5-carbaldehyde: (i) $\mathrm{POCl}_{3}, \mathrm{DMF}, \mathrm{rt}, 15 \mathrm{~min}, 100{ }^{\circ} \mathrm{C}$, $4 \mathrm{~h}$, yield $=60 \%$; (ii) $p$ - TsCl, dry pyridine, DMAP, dry $\mathrm{CHCl}_{3}, 0{ }^{\circ} \mathrm{C}, 6 \mathrm{~h}$, yield =92\%; (iii) $\mathrm{HO}\left(\mathrm{CH}_{2} \mathrm{CH}_{2} \mathrm{O}\right)_{n} \mathrm{H}(n=2,3$ and 4), dry 1,4-dioxane, reflux, $4 \mathrm{~h}$, yield = 80-90\%; (iv) phthalimide, diisopropyl azodicarboxylate (DIAD), triphenylphosphine, dry DMF, rt, $4 \mathrm{~h}$, yield =95$97 \%$; (v) hydrazine monohydrate, pyridine, rt, $24 \mathrm{~h}$, yield $=82-85 \%$; (vi) 2,4,6-trichloro-pyrimidine-5-carbaldehyde (2), N,N-diisopropylethylamine, dry $\mathrm{CH}_{2} \mathrm{Cl}_{2}, \mathrm{rt}, 6 \mathrm{~h}$, yield $=80-85 \%$. 
derivatives of 2,4,6-trichloro-pyrimidine-5-carbaldehyde. ${ }^{92}$ They self-assemble in hydrocarbons to result in $\beta$-sheet type extensive hydrogen-bonded organizations which finally lead to the formation of various interesting gel superstructures depending upon the choice of the L-amino acid based spacer. However, the self-assembly of the 2,4,6-trichloro-pyrimidine5-carbaldehyde derivative containing a rigid cholesterol residue is still unknown. Herein, we report the first synthesis of pyrimidine derivatives which contain cholesterol residue attached to the pyrimidine core via oligo-oxyethylene spacers of various lengths (Scheme 1). The length of the oxyethylene spacer was varied in order to understand the effect of such spacers on the gelation process. The main objective of the present work is to design and synthesize a multifunctional material that is capable of showing gelation and mesogenic behaviour induced by an external stimulus. For this purpose, cholesterol units were covalently incorporated into the supramolecular building block to achieve gelation. At the same time, the insertion of oxyethylene chains as a spacer between the cholesterol unit and the pyrimidine moiety offers an opportunity to exploit alkali metal ion induced propagation of the liquid-crystalline behaviour in the solid state. To the best of our knowledge this is the first report which shows modulation of the gelation properties by varying the length of the oxyethylene spacer. This is also the first instance where it has been possible to achieve gelation and manifest alkali metal ion induced liquid crystallinity from the same series of compounds.

\section{Results and discussion}

\section{Synthesis}

A series of cholesteryl derivatives of 2,4,6-trichloro-pyrimidine5 -carbaldehyde was synthesized (Scheme 1). Cholesterol was converted to cholesteryl $p$-toluenesulfonate (tosylate) (3) in the presence of pyridine and a catalytic amount of DMAP. Then, cholesteryl tosylate was further heated in the presence of an excess of individual oxyethylene diols to obtain various alcohols $(\mathbf{4 a - c})$. These alcohols were converted to the corresponding phthalimide derivatives (5a-c) using triphenylphosphine and diisopropyl azodicarboxylate (DIAD) in DMF based on the Mitsunobu reaction. These phthalimide derivatives were subsequently transformed to the corresponding amines (6a-c) using hydrazine monohydrate in pyridine. Finally, the resulting amines were treated with 2,4,6-trichloropyrimidine-5-carbaldehyde in the presence of diisopropylethylamine in $\mathrm{CH}_{2} \mathrm{Cl}_{2}$ to get the final products (1a-c). Each new compound and the intermediates were characterized by FT-IR, ${ }^{1} \mathrm{H}$ and ${ }^{13} \mathrm{C}-\mathrm{NMR}$ spectroscopy and ESI-MS (see the Experimental section, ESI†).

In the following sections, we report the physical characterization of different modes of aggregation of different compounds (1a-c) given in Scheme 1, in various organic solvents and in the solid state. We also investigate the role of the oxyethylene spacer in the self-assembly process of the above molecules and document their properties herein.

\section{Gelation experiment}

First, the gelation ability of these compounds 1a-c was evaluated in different organic solvents by the "stable-to-inversion protocol of a test tube" method. 1a immobilized organic solvents such as $n$-butanol (Fig. 1) and $n$-dodecane. The minimum gelator concentration (mgc) associated with the gel formation in $n$-butanol ( $3.6 \mathrm{mM})$ was lower compared to that in $n$-dodecane (4.6 mM). The characteristics of compounds $1 \mathrm{a}-\mathbf{c}$ in different solvents are listed in Table S1 (ESI $\dagger$ ). They, however, precipitated from their solutions in $t$-butanol or $n$-hexane and were found to be soluble in each of $\mathrm{CH}_{2} \mathrm{Cl}_{2}, \mathrm{CHCl}_{3}, \mathrm{THF}$, benzene and toluene. Surprisingly, none of the other members in this series with longer oxyethylene spacers induced gelation in any of these solvents. An increase in the length of the oxyethylene spacer probably enhanced the extent of degrees of freedom of the cholesterol moiety, resulting in 'looser' packing of the cholesteryl derivatives. Compounds $\mathbf{1 b}$ and $\mathbf{1 c}$ with longer oxyethylene spacers ( $n=3$ and 4 ) resulted in solutions and precipitates in $n$-butanol and $n$-dodecane respectively. This result clearly indicates that the increase in the length of the oxyethylene spacer enhances the polarity of these compounds. Hence, the solubility associated with the spacer lengths of this series of compounds also plays an important role in the gelation process.

\section{Morphological behaviour}

To reveal the microstructures of organogels of 1a in $n$-butanol and $n$-dodecane, scanning electron microscopy (SEM) and atomic force microscopy (AFM) were performed. SEM images of the xerogels of 1a obtained from $n$-butanol (Fig. 2a) and $n$ dodecane (Fig. 2b) showed fibrous structures of high aspect ratio. The AFM images of the xerogels of 1a obtained from $n$ butanol and $n$-dodecane also exhibited fibrous structures of high aspect ratio and diameters ranged from 100-200 nm (Fig. 2c and d). However, it is important to note that drying of the gel samples during xerogel preparation may induce artifacts as well.

\section{UV-Vis and CD-spectroscopy}

In order to understand the nature of inter-molecular interactions in the supramolecular aggregates, a temperature-dependent UV-Vis absorption spectroscopic study was performed (S1a and $\mathrm{b}, \mathrm{ESI} \dagger) .{ }^{92}$ We avoided the spectroscopic investigation at

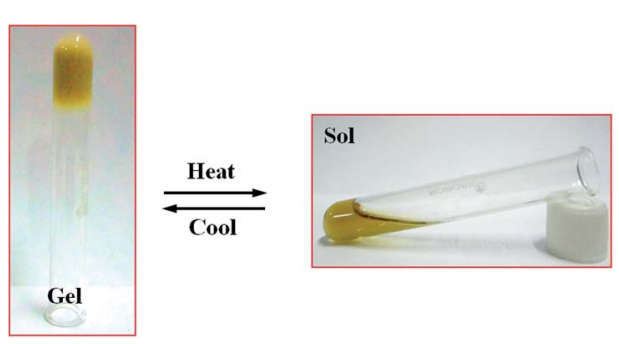

Fig. 1 Photographs showing the temperature induced gel-to-sol transition of $1 \mathrm{a}(3.6 \mathrm{mM})$ in $n$-butanol. 


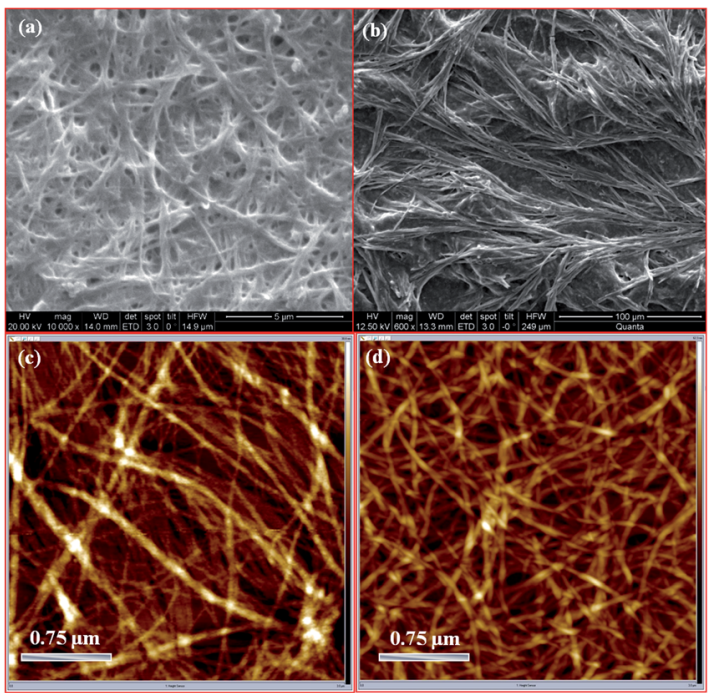

Fig. 2 ( $a$ and b) SEM and ( $c$ and d) AFM images of the xerogels of 1a obtained from $n$-butanol and $n$-dodecane respectively at concentrations of 3.6 and $4.6 \mathrm{mM}$ respectively.

higher concentrations because of the high scattering under such conditions due to the opaque nature of the gel. Since aggregates still persisted at lower concentrations, the temperature-dependent UV-Vis spectra of $1 \mathbf{a}$ were recorded using less concentrated solution. ${ }^{19}$ The UV-Vis spectrum of 1a in $n$-butanol at a concentration of $0.046 \mathrm{mM}$ showed a broad peak in the range of $220-240 \mathrm{~nm}$ which may be attributed to the $\mathrm{n}-\pi^{*}$ transition of the $\mathrm{C}=\mathrm{N}$ and $\mathrm{C}=\mathrm{C}$ bonds (Fig. S1a, ESI $\dagger$ ). ${ }^{93}$ In addition, two sharp peaks near 275 and $315 \mathrm{~nm}$ were also observed which most likely originated from the $\pi-\pi^{*}$ transition of the aromatic ring and $n-\pi *$ transition of the formyl substituent respectively. ${ }^{93}$ The intensity of these absorption spectral bands monotonically increased with the increase in temperature and finally became saturated at approximately $60{ }^{\circ} \mathrm{C}$. This was due to a likely consequence of the weakening of the noncovalent interactions between the chromophores. ${ }^{19}$ This resulted in the breaking of larger aggregates to form aggregates of smaller sizes. A similar pattern was also observed in the temperature-dependent UV-Vis spectra of 1a in $n$-dodecane (Fig. S1b, ESI†).

The manifestation of the supramolecular chirality at the molecular level induced by the presence of the cholesterol moiety due to the formation of a self-assembly associated with the sol-to-gel transition process was investigated by circular dichroism (CD) spectroscopy (Fig. 3a and b). Fig. 3a illustrates the temperature-dependent changes in the CD spectra of 1a in $n$-butanol at $0.046 \mathrm{mM}$. It exhibited two positive Cotton effects near 345 and $288 \mathrm{~nm}$ indicating a clockwise orientation of the dipole moments in the supramolecular aggregates..$^{94,95}$ The two positive peak intensities near 345 and $288 \mathrm{~nm}$ monotonically decreased with the increase in temperature presumably because of the loss of the supramolecular chirality. This indicates that the supramolecular chirality of the self-assembled aggregates is responsible for the observed CD-signal. ${ }^{96,97}$ The transition temperature $\left(c a .45^{\circ} \mathrm{C}\right)$ was calculated from the plot of the $\mathrm{CD}$
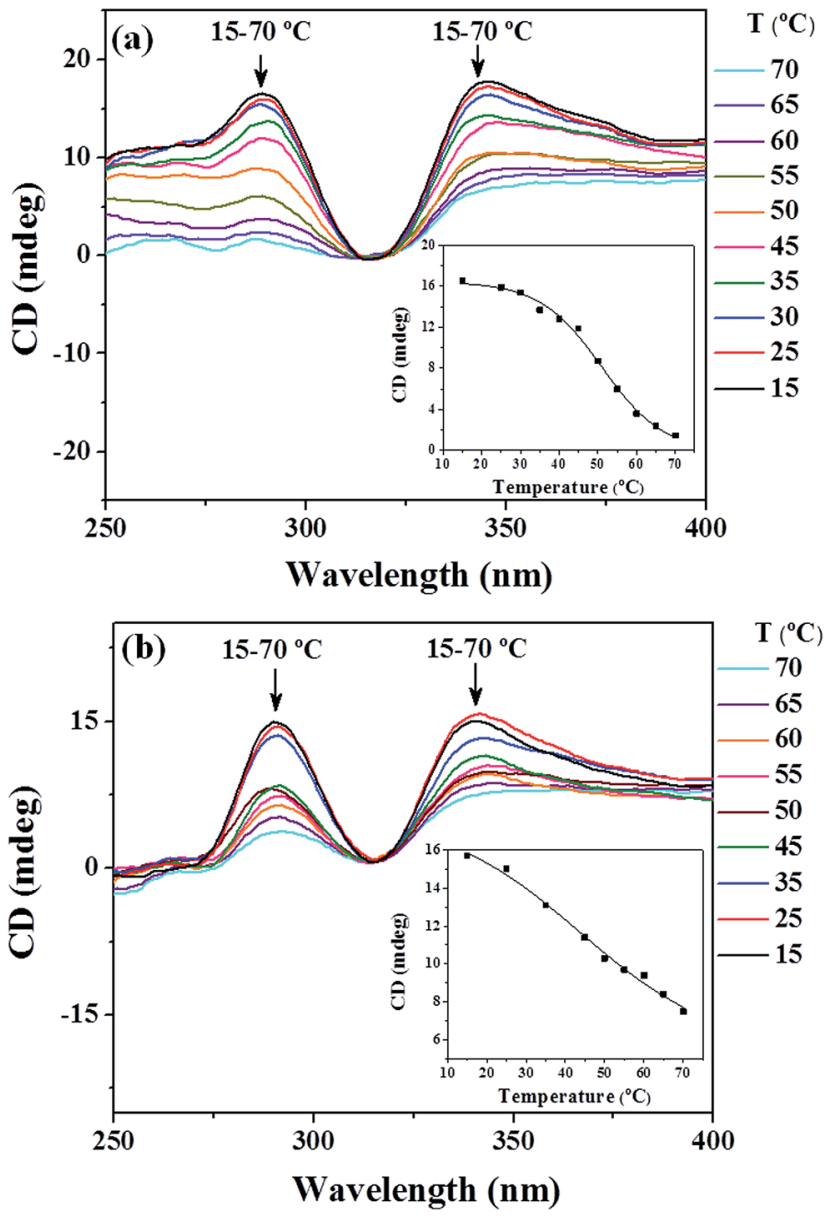

Fig. 3 Temperature-dependent changes in the CD-spectra of 1a in (a) $n$-butanol and (b) $n$-dodecane at a concentration of $0.046 \mathrm{mM}$. Insets show the plot of CD (mdeg) vs. temperature at $345 \mathrm{~nm}$.

intensity at $345 \mathrm{~nm} v s$. temperature for the disruption of the self-assembly to smaller aggregates (inset, Fig. 3a). A similar pattern was also observed in the temperature-dependent CDspectra of 1a in $n$-dodecane, thus elucidating the presence of similar motifs in the self-assembly process (Fig. 3b).

\section{Thermal response to mesophase behaviour in the presence of alkali metal ions}

The solid state behaviours of these cholesteryl derivatives, 1a-c possessing di-, tri- and tetra-oxyethylene units and their associated alkali metal ion complexes were investigated by various physical methods including polarizing optical microscopy (POM), solid phase differential scanning calorimetry (DSC) and wide-angle X-ray diffraction (WAXD) experiments. ${ }^{98-100}$ Alkali metal complexes of this series of compounds were prepared by evaporation of the THF solution of each derivative with appropriate stoichiometry of the perchlorate salt of the alkali metal.

In the POM experiment, each sample was first heated to obtain an isotropic melt and then cooled down slowly $\left(5{ }^{\circ} \mathrm{C}\right.$ $\mathrm{min}^{-1}$ ) to room temperature. Various types of phases appeared during cooling of the isotropic melts of compounds 1a-c at 65, 70 and $80{ }^{\circ} \mathrm{C}$ respectively (Fig. $4 \mathrm{a}-\mathrm{c}$ ). Interestingly, dramatic 


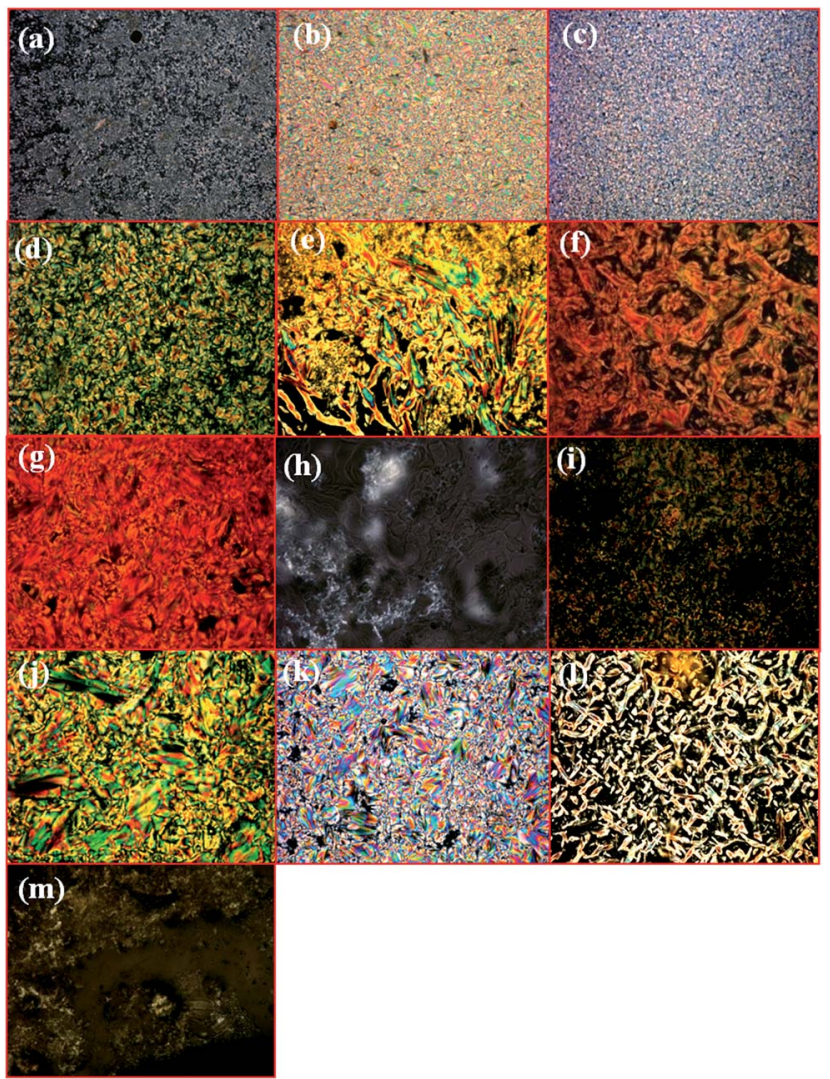

Fig. 4 POM images of (a) 1a, (b) $1 \mathrm{~b}$, (c) $1 \mathrm{c}$, (d) $1 \mathrm{~b}-\mathrm{Na}^{+}(0.5$ equiv.), (e) $1 b-\mathrm{Na}^{+}$(1 equiv.), (f) $1 \mathrm{~b}-\mathrm{Li}^{+}\left(0.5\right.$ equiv.), (g) $1 \mathrm{~b}-\mathrm{Li}^{+}$(1 equiv.), (h) $1 \mathrm{~b}-\mathrm{Mg}^{2+}$ (1 equiv.), (i) $1 \mathrm{c}-\mathrm{Na}^{+}\left(0.5\right.$ equiv.), (j) $1 \mathrm{c}-\mathrm{Na}^{+}$(1 equiv.), (k) $1 \mathrm{c}-\mathrm{Li}^{+}(0.5$ equiv.), (l) $1 \mathrm{c}-\mathrm{Li}^{+}$(1 equiv.) and ( $\left.\mathrm{m}\right) 1 \mathrm{c}-\mathrm{Mg}^{2+}$ (1 equiv.) obtained on cooling isotropic phases. Magnification 20x.

changes in the birefringence and the morphology of the mesophases were observed with $\mathbf{1 b}$ and $\mathbf{1 c}$ in the presence of 0.5 and 1 equiv. of $\mathrm{Li}^{+}$or $\mathrm{Na}^{+}$ions presumably because of the complexation with the oxyethylene chain (Fig. $4 \mathrm{~d}-\mathrm{g}$ and $\mathrm{i}-\mathrm{l}$ ). In contrast, compound 1a underwent an apparent decomposition under these conditions. All of these samples remained as viscous liquid above $\sim 130{ }^{\circ} \mathrm{C}$ and the liquid-crystalline nature of the samples was confirmed by scratching. Addition of excess alkali metal salt disrupted the mesophase formation.

Interestingly, the presence of $\mathrm{Mg}^{2+}$ resulted in the decomposition of these compounds probably due to the high charge density of the $\mathrm{Mg}^{2+}$ ion (Fig. $4 \mathrm{~h}$ and $\mathrm{m}$ ). It is also important to note that compounds 1a-c became isotropic below $100{ }^{\circ} \mathrm{C}$ whereas alkali metal complexes transformed to isotropic melts above $150{ }^{\circ} \mathrm{C}$ under POM. This observation is in accordance with the results obtained by Kato and co-workers. ${ }^{\mathbf{8 4}}$

In the first heating cycle of the DSC experiment, the sample was heated to remove the anisotropic history of the sample. The resulting melt was cooled down at a rate of $5{ }^{\circ} \mathrm{C} \mathrm{min}^{-1}$. After the sample reached room temperature, new heating and cooling cycles were performed under the same conditions as before. The DSC profile of compound 1a showed a broad endothermic transition consisting of two closely placed peaks at 64 and $70{ }^{\circ} \mathrm{C}$ respectively (Fig. S2, ESI $\dagger$ ). However, compounds $\mathbf{1 b}$ and $\mathbf{1 c}$ exhibited single endothermic transitions at 75 and $85{ }^{\circ} \mathrm{C}$ respectively. In cooling cycles compound 1a showed double exothermic transitions at 58 and $66^{\circ} \mathrm{C}$ similarly to the heating cycle. However, single exothermic transitions were observed at 71 and $81{ }^{\circ} \mathrm{C}$ respectively for compounds $\mathbf{1 b}$ and $\mathbf{1 c}$.

Under the same circumstances, interesting and drastic changes were observed in the DSC profiles of $\mathbf{1} \mathbf{b}-\mathbf{c}$ in the presence of alkali metal ions (Fig. S3a-d, ESI $\dagger$ ). Fig. S3a and b (ESI $\dagger$ ) show DSC thermograms during heating and cooling of $\mathbf{1 b}$ and 1c in the presence of one equiv. of $\mathrm{LiClO}_{4}$. The heating cycles exhibited multiple weak transitions in the range of 150-175 and 140-185 ${ }^{\circ} \mathrm{C}$. On the other hand, small peaks associated with exothermic transitions of liquid-crystalline phases appeared in the cooling cycles in the range of $120-170$ and $125-190{ }^{\circ} \mathrm{C}$. Similar patterns were obtained in the case of $\mathrm{Na}^{+}$-complexes of 1b and 1c (Fig. S3c and d, ESI $\dagger$ ). Such kinds of multiple transitions were observed for bent core liquid-crystalline compounds based on a 1,3-dihydroxybenzene core containing a cholesteryl 6-oxyhexanoate wing. ${ }^{101}$ Park et al. also found similar types of multiple transitions in the DSC experiment of $\mathrm{Cu}$ (II) complexes of certain pyridyl ligands. ${ }^{\mathbf{1 0 2}}$

\section{Structural analysis and molecular modelling}

Wide-angle X-ray diffraction (WAXD) was carried out to acquire information about the packing patterns in the supramolecular assembly present in the xerogel and in the solid state. In the WAXD pattern of the xerogel of 1 a derived from $n$-butanol, three reflections corresponding to the $d$-spacings of 24,15 and $12 \AA$ were obtained (Fig. 5). The relative positions of these reflections at $\sqrt{ } 1, \sqrt{ } 3$ and $\sqrt{ } 4$ are in good agreement with the (100), (110) and (200) planes, respectively. This indicates the formation of a columnar hexagonal phase $\left(\mathrm{Col}_{\mathrm{h}}\right)$ with a lattice constant of 27.7 A. ${ }^{5,6,71,103,104}$ Similarly, the xerogel of 1 a obtained from $n$-dodecane showed three peaks associated with the $d$-spacings of $19 \AA$, $12 \AA(1: \sqrt{ } 3)$ and $9 \AA(1: \sqrt{ } 4)$, indicating the presence of a hexagonal columnar structure $\left(\mathrm{Col}_{\mathrm{h}}\right)$ with a lattice constant of $21.9 \AA$ (Fig. 5). The WAXD data of the xerogels are summarized

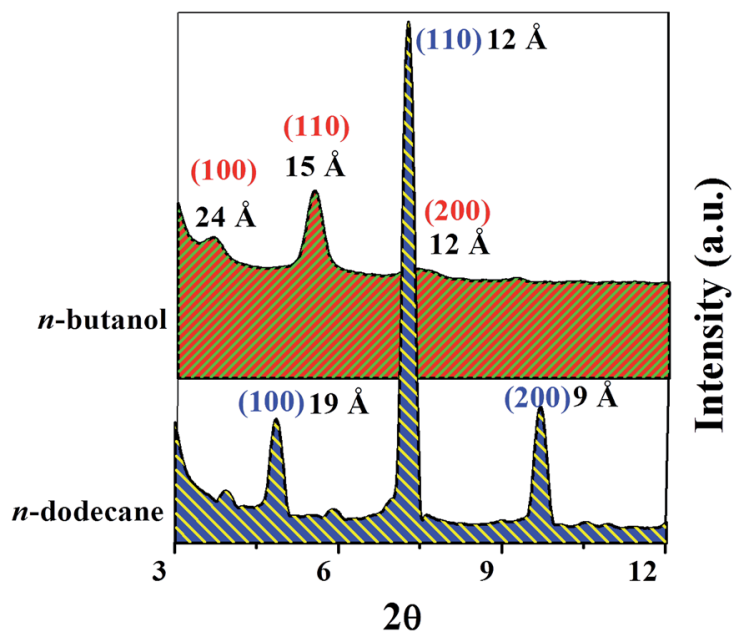

Fig. 5 WAXD plots of xerogels of 1 a obtained from $n$-butanol and $n$ dodecane. 
in Table S2 (ESI $\dagger$ ). Interestingly, the longest repeat distance associated with the first diffraction peak of the xerogel of 1a obtained from $n$-butanol is much larger than that obtained from $n$-dodecane. The higher hydrophobicity of $n$-dodecane presumably drives the oxyethylene spacer to loop inside which leads to shortening of the repeat distance.

The modes of self-assembly in the solid state of compounds 1a-c and their alkali metal complexes were also investigated by WAXD [Fig. 6 and S4 (ESI $\dagger$ )]. Samples were annealed at their associated isotropic temperatures before recording their wideangle X-ray diffractograms. In the WAXD plot of 1a, three peaks appeared corresponding to the $d$-spacings of 22, 14 and $11 \AA$ [Fig. 6a and b and S4a (ESI $\dagger)$ ]. These reflections were indexed in sequence as the (100), (110), and (200) planes, due to a columnar hexagonal lattice with the lattice parameter of $a$ $=25.4 \AA .^{5,6,71,103,104}$ Similarly compounds $\mathbf{1 b}$ and $\mathbf{1 c}$ showed hexagonal columnar structures with the lattice parameters of 28.3 and $28.5 \AA$ A respectively [Fig. $6 \mathrm{a}$ and b and S4a (ESI $\dagger$ )]. The WAXD data of the compounds 1a-c are summarized in Table S3 (ESI $\dagger$ ).
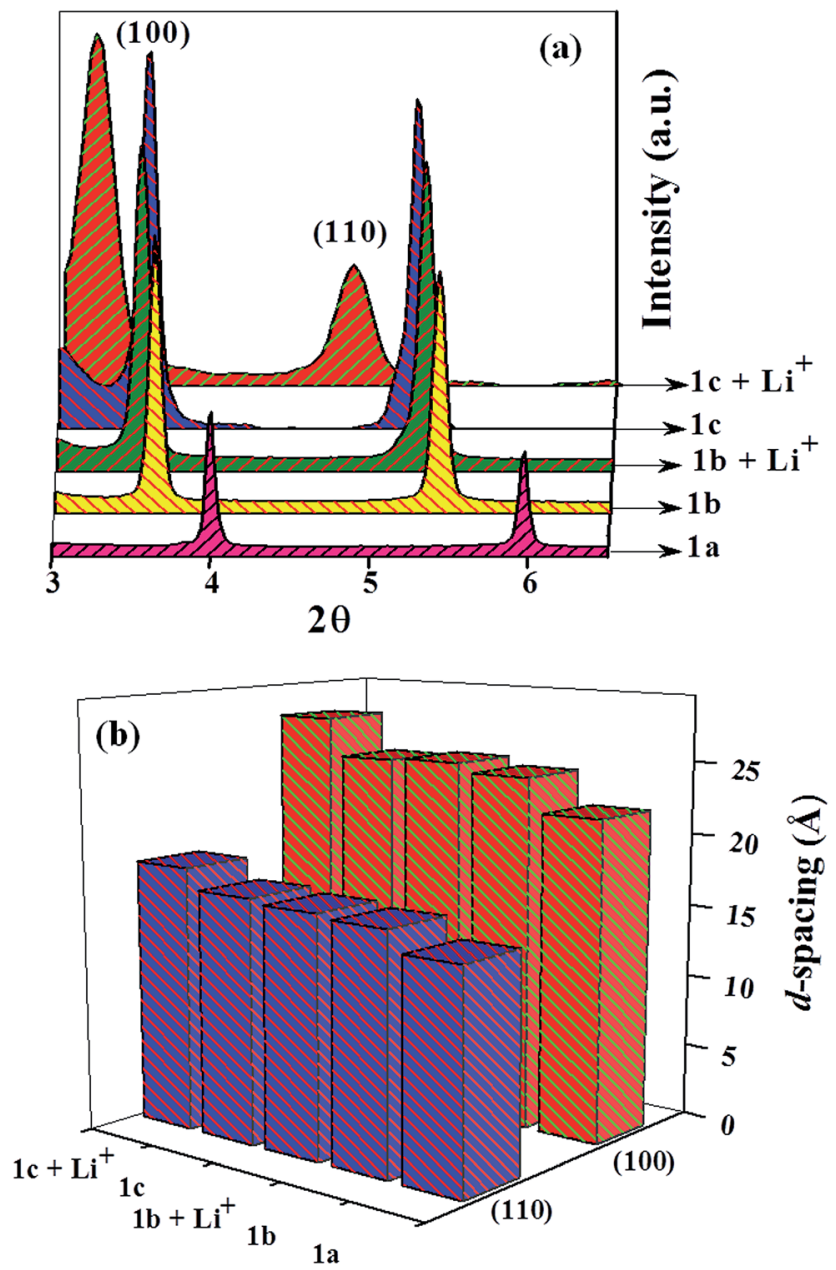

Fig. 6 (a) WAXD plots of $1 \mathrm{a}-\mathrm{c}$ and $1 \mathrm{~b}-\mathrm{Li}^{+}$(1 equiv.) and $1 \mathrm{c}-\mathrm{Li}^{+}$(1 equiv.) in the solid state; (b) $d$-spacings associated with (100) and (110) reflections of the hexagonal columnar structure of $1 \mathrm{a}-\mathrm{c}$ and $1 \mathrm{~b}-\mathrm{Li}^{+}(1$ equiv.) and $1 \mathrm{c}-\mathrm{Li}^{+}$(1 equiv.).
It is reported that poly(ethylene glycol) (PEG) and polyethylene oxide (PEO) acquire helical and coiled conformations ${ }^{\mathbf{1 0 5}}$ and the average width of the single helix of PEO is $7.6 \AA$ from its STM measurements. ${ }^{106}$ The oxygen atoms in the oxyethylene chains coordinate with alkali metal ions by ion-dipole interactions, ${ }^{107}$ leading to straightening of the bent, coiled PEO segments. ${ }^{85}$ Since the alkali metal ion coordinates with the ' $\mathrm{O}$ ' atoms of the oxyethylene chain, the $\mathrm{ClO}_{4}{ }^{-}$prefers to stay in the inter-disk region in order to stabilize the $\mathrm{Col}_{\mathrm{h}}$ structure in the alkali metal complexes (Fig. 7).

Interestingly, the basic hexagonal columnar structural patterns of $\mathbf{1 b}$ and $\mathbf{1 c}$ remained unaffected in the presence of one equiv. of $\mathrm{LiClO}_{4}$ [Fig. 6a and $\mathrm{S} 4 \mathrm{a}(\mathrm{ESI} \dagger)$ ]. This result is in agreement with previous findings of Kato and co-workers. ${ }^{\mathbf{8 4}}$ However, the $d$-spacings appeared at 24.5 and $24.7 \AA$ associated with the (100) reflection of $\mathbf{1 b}$ and $\mathbf{1 c}$ increased to 24.9 and $27 \AA$ respectively in the presence of one equivalent of $\mathrm{LiClO}_{4}$ (Fig. $6 \mathrm{a}$ and b). Hence, the lattice parameter increased to $28.8 \AA$ for $\mathbf{1 b}$ and $31.2 \AA$ for $1 \mathrm{c}$ after $\mathrm{Li}^{+}$coordination. The WAXD data of the $\mathrm{Li}^{+}$-complexes of 1a-c are summarized in Table S3 (ESI $\dagger$ ). This observation emphasizes that the oxyethylene units remain in coil-like conformation under ion-free conditions and get extended by the coordination of the alkali metal ions increasing the diameter of the disc (Fig. 7). This observation is in good agreement with the results reported by Kohmoto and coworkers. ${ }^{85}$ The WAXD data of the $\mathrm{Li}^{+}$-complexes of compounds

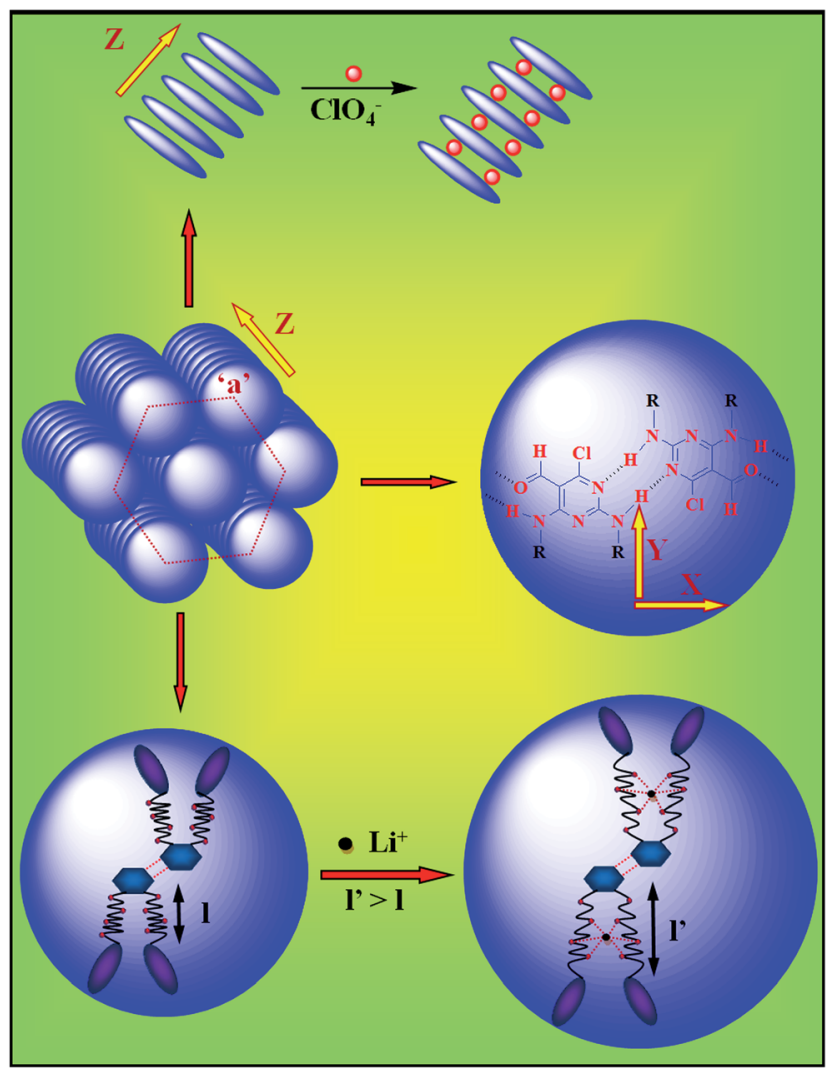

Fig. 7 A proposed model of a hexagonal columnar ( $\mathrm{Col}_{h}$ ) type aggregation pattern composed of dimeric assemblies as building blocks and elongation of oxyethylene units due to coordination with $\mathrm{Li}^{+}$. 
1a-c are summarized in Table S3 (ESI $\dagger$ ). Similar results were also obtained for the $\mathrm{Na}^{+}$-complexes (Table S4, ESI $\dagger$ ). The lattice parameter increased to $28.5 \AA$ for $\mathbf{1 b}$ and $29.9 \AA$ for $\mathbf{1 c}$ after $\mathrm{Na}^{+}$ coordination. It is important to note that the maximum elongation of the $d$-spacing was observed for $1 \mathrm{c}$ in the presence of 1 equiv. of $\mathrm{Li}^{+}$. This has also been reflected in the POM image of 1c-Li ${ }^{+}$(Fig. 4l).

Hence, it is clearly evident that the liquid-crystalline states of the compounds alone do not stabilize. That is why cooling of the isotropic liquid leads to direct crystallization to more stabilized forms. However, the liquid-crystalline states are stabilized due to the ion-dipole interaction in the case of their alkali metal complexes.

Since the structures of the steroid amphiphiles are not disklike, one may assume that a column slice comprises more than one molecule. The number $(n)$ of molecules constituting a single disk of the column could be estimated according to eqn (1). ${ }^{103,104}$

$$
n=\left(a^{2}\right)(\sqrt{ } 3 / 2)\left(h \rho N_{\mathrm{A}} / M\right)
$$

where the notation ' $a$ ' is the hexagonal lattice parameter, $N_{\mathrm{A}}$ is Avogadro's number and $M$ is the molecular mass of the amphiphile. The thickness $(h)$ of a slice is about $5.5 \AA$, calculated on the basis of wide-angle X-ray diffractograms [Fig. S4b $(\mathrm{ESI} \dagger)]{ }^{103,104}$ Assuming a density $(\rho)$ of $1 \mathrm{~g} \mathrm{~cm}^{-3}$, the estimated number of molecules $(n)$ in a disk in the columnar hexagonal state is approximately 2 in each case (Fig. 7). Hence each disk of the hexagonal columnar structure is composed of dimeric assemblies of the amphiphilic molecules since pyrimidine derivatives are well-known to form complementary $\mathrm{H}$-bonded structures. ${ }^{\text {91,92,108-110 }}$

Previously, we have shown possible complementary hydrogen-bonding interactions of similar pyrimidine derivatives, which occur through the participation of $\mathrm{sp}^{2}$-hybridized ring nitrogen atoms, $-\mathrm{NH}$, and aldehyde groups. On the basis of these results a model of formation of the dimeric assemblies leading to the hexagonal columnar structure is proposed (Fig. 7). ${ }^{91,92,108-110}$

\section{Conclusions}

In summary, we have described the syntheses of a new family of cholesterol appended 2,4,6-trichloropyrimidine-5-carbaldehyde derivatives, 1a-c, tailored with variable lengths of oxyethylene spacers. Only 1a with the shortest spacer $(n=2)$ acts as a gelator in organic solvents such as $n$-butanol and $n$-dodecane. The selfassembly of 1a in these solvents is driven by both hydrogen bonding and lipophilic interactions among the gelator molecules. To the best of our knowledge this is the first report where it has been possible to modulate the gelation properties by varying the lengths of the oxyethylene type spacer.

The mode of aggregation of $\mathbf{1 a}$ in organic solvents has been investigated by temperature-dependent UV-Vis and CD spectroscopy. Morphological investigations of the xerogels under SEM and AFM reveal the presence of fibrous structures with high aspect ratio. Wide-angle X-ray diffraction (WAXD) analysis of the xerogels confirms the presence of dimeric molecular assemblies. This eventually propagates in the orthogonal direction to develop into hexagonal columnar structures $\left(\mathrm{Col}_{h}\right)$. In our previous report, we have shown that grafting of hydrocarbon chains with the 2,4,6-trichloro-pyrimidine-5-carbaldehyde template leads to the formation of a lamellar self-assembly in the xerogel. ${ }^{92}$ Hence, the present work sheds new light on the field of self-assembly, in which the structure of the supramolecular assembly could be modulated by the choice of the substituents. This is also a rare instance in which the solvent polarity results in a significant change in the conformation of the oxyethylene spacer of gelator 1a. This was manifested in the form of an increase in the diameter of the disk in the xerogel upon changing the solvent from $n$-dodecane to $n$-butanol.

Insertion of an oxyethylene type spacer offers an opportunity to tune their solid state properties by the addition of alkali metal ions. Complexation of $\mathbf{1 b}-\mathbf{c}(n=3$ and 4$)$ with $\mathrm{Li}^{+}$or $\mathrm{Na}^{+}$ results in dramatic changes in the optical birefringence and the morphology of the mesophases as revealed by polarized optical microscopy (POM). It may be noted that differential scanning calorimetry (DSC) traces of the alkali metal ion complexes are entirely different from those of the compounds alone. The hexagonal columnar structure of the aggregates present in the mesophases of these compounds and their associated $\mathrm{Li}^{+}$and $\mathrm{Na}^{+}$complexes have been analyzed by WAXD. Elongation of the coil like oxyethylene spacers occurs presumably due to the coordination with $\mathrm{Li}^{+}$or $\mathrm{Na}^{+}$. However, the basic pattern of the hexagonal columnar organizations remains unaffected. This is the first example of a series of oxyethylene chain integrated cholesteryl derivatives which could be employed in tuning their solid state properties by recognition of specific alkali metal ions.

\section{Acknowledgements}

This work was supported by the Department of Science and Technology (J. C. Bose Fellowship to S. B.), Government of India, New Delhi, India. S. D. thanks CSIR for a senior research fellowship.

\section{Notes and references}

1 J. Han, J. Mater. Chem. C, 2013, 1, 7779.

2 Y. Yan, Y. Lin, Y. Qiao and J. Huang, Soft Matter, 2011, 7, 6385.

3 T. Yamazaki, H. Fenniri and A. Kovalenko, ChemPhysChem, 2010, 11, 361.

4 G. Tikhomirov, T. Yamazaki, A. Kovalenko and H. Fenniri, Langmuir, 2008, 24, 4447.

5 S. Laschat, A. Baro, N. Steinke, F. Giesselmann, C. Hägele, G. Scalia, R. Judele, E. Kapatsina, S. Sauer, A. Schreivogel and M. Tosoni, Angew. Chem., Int. Ed., 2007, 46, 4832.

6 T. Kato, N. Mizoshita and K. Kishimoto, Angew. Chem., Int. Ed., 2006, 45, 38.

7 H. Fenniri, P. Mathivanan, K. L. Vidale, D. M. Sherman, K. Hallenga, K. V. Wood and J. G. Stowell, J. Am. Chem. Soc., 2001, 123, 3854. 
8 G. Mieden-Gundert, L. Klein, M. Fischer, F. Vögtle, K. Heuzé, J.-L. Pozzo, M. Vallier and F. Fages, Angew. Chem., Int. Ed., 2001, 40, 3164.

9 S. Park and B.-K. Cho, Soft Matter, 2015, 11, 94.

10 C.-C. Huang, C.-C. Hsu, L.-W. Chen and Y.-L. Cheng, Soft Matter, 2014, 10, 9343.

11 R. Mezzenga, J. Ruokolainen, N. Canilho, E. Kasëmi, D. A. Schlüter, W. B. Lee and G. H. Fredrickson, Soft Matter, 2009, 5, 92.

12 A. Kotlewski, B. Norder, W. F. Jager, S. J. Picken and E. Mendes, Soft Matter, 2009, 5, 4905.

13 T. Kato, Science, 2002, 295, 2414.

14 J. W. Steed, Chem. Commun., 2011, 47, 1379.

15 Y. Lin, Y. Qiao, P. Tang, Z. Li and J. Huang, Soft Matter, 2011, 7, 2762.

16 J. A. Sáez, B. Escuder and J. F. Miravet, Chem. Commun., 2010, 46, 7996.

17 P. Terech and R. G. Weiss, Chem. Rev., 1997, 97, 3133.

18 Y. Li, L. Cheng, C. Liu, Y. Xie, W. Liu, Y. Fan, X. Li and X. Fan, Soft Matter, 2014, 10, 8261.

19 S. Datta and S. Bhattacharya, Chem. Commun., 2012, 48, 877.

20 P. Sahoo, R. Sankolli, H.-Y. Lee, S. R. Raghavan and P. Dastidar, Chem.-Eur. J., 2012, 18, 8057.

21 A. Dawn, T. Shiraki, S. Haraguchi, S.-i. Tamaru and S. Shinkai, Chem.-Asian J., 2011, 6, 266.

22 G. O. Lloyd and J. W. Steed, Nat. Chem., 2009, 1, 437.

23 Y. Kim, M. Wada and N. Tamaoki, J. Mater. Chem. C, 2014, 2, 1921.

24 Y. A. Getmanenko, S.-W. Kang, N. Shakya, C. Pokhrel, S. D. Bunge, S. Kumar, B. D. Ellman and R. J. Twieg, J. Mater. Chem. C, 2014, 2, 2600.

25 L. D. Sio, G. Palermo, V. Caligiuri, A. E. Vasdekis, A. Pane, J.-W. Choi, L. Maffli, M. Niklaus, H. R. Shea and C. Umeton, J. Mater. Chem. C, 2013, 1, 7798.

26 H. Basit, A. Pal, S. Sen and S. Bhattacharya, Chem.-Eur. J., 2008, 14, 6534.

27 S. Bhattacharya, A. Srivastava and A. Pal, Angew. Chem., Int. Ed., 2006, 45, 2934.

28 A. R. Hirst, B. Escuder, J. F. Miravet and D. K. Smith, Angew. Chem., Int. Ed., 2008, 47, 8002.

29 J. H. Jung, J. H. Lee, J. R. Silverman and G. John, Chem. Soc. Rev., 2013, 42, 924.

30 M.-O. M. Pipenbrock, G. O. Lloyd, N. Clarke and J. W. Steed, Chem. Rev., 2010, 110, 1960.

31 H. Yang, T. Yi, Z. Zhou, Y. Zhou, J. Wu, M. Xu, F. Li and C. Huang, Langmuir, 2007, 23, 8224.

32 P. Mukhopadhyay, Y. Iwashita, M. Shirakawa, S.-i. Kawano, N. Fujita and S. Shinkai, Angew. Chem., Int. Ed., 2006, 45, 1592.

33 M. D. Segarra-Maset, V. J. Nebot, J. F. Miravet and B. Escuder, Chem. Soc. Rev., 2013, 42, 7086.

34 L. Jiang, Y. Yan and J. Huang, Soft Matter, 2011, 7, 10417. 35 M. Shirakawa, N. Fujita, T. Tani, K. Kaneko, M. Ojima, A. Fujii, M. Ozaki and S. Shinkai, Chem.-Eur. J., 2007, 13, 4155 .
36 K. Sugiyasu, N. Fujita and S. Shinkai, J. Mater. Chem., 2005, 15, 2747.

37 J.-E. S. Sohna and F. Fages, Chem. Commun., 1997, 327.

38 J. Nanda, A. Biswas, B. Adhikari and A. Banerjee, Angew. Chem., Int. Ed., 2013, 52, 1.

39 J. F. Miravet and B. Escuder, Chem. Commun., 2006, 5796.

40 N. Komiya, T. Muraoka, M. Iida, M. Miyanaga, K. Takahashi and T. Naota, J. Am. Chem. Soc., 2011, 133, 16054.

41 X. Sui, X. Feng, M. A. Hempenius and G. J. Vancso, J. Mater. Chem. B, 2013, 1, 1658.

42 Q. Lin, X. Zhu, Y.-P. Fu, Y.-M. Zhang, R. Fang, L.-Z. Yang and T.-B. Wei, Soft Matter, 2014, 10, 5715.

43 S. Basak, J. Nanda and A. Banerjee, Chem. Commun., 2014, 50, 2356.

44 K. Fan, J. Yang, X. Wang and J. Song, Soft Matter, 2014, 10, 8370 .

45 U. K. Das, S. Banerjee and P. Dastidar, Chem.-Asian J., 2014, 9, 2475.

46 V. J. Nebot, J. Armengol, J. Smets, S. F. Prieto, B. Escuder and J. F. Miravet, Chem.-Eur. J., 2012, 18, 4063.

47 M. Suzuki and K. Hanabusa, Chem. Soc. Rev., 2009, 38, 967.

48 M. George, S. L. Synder, P. Terech, C. J. Glinka and R. G. Weiss, J. Am. Chem. Soc., 2003, 125, 10275.

49 T. Kato, T. Kutsuna, K. Hanabusa and M. Ukon, Adv. Mater., 1998, 10, 606.

50 S. Bhattacharya and S. N. G. Acharya, Chem. Mater., 1999, 11, 3121.

51 F. Rodríguez-Llansola, D. Hermida-Merino, B. NietoOrtega, F. J. Ramírez, J. T. L. Navarrete, J. Casado, I. W. Hamley, B. Escuder, W. Hayes and J. F. Miravet, Chem.-Eur. J., 2012, 18, 14725.

52 G. John, S. R. Jadhav, V. M. Menon and V. T. John, Angew. Chem., Int. Ed., 2012, 51, 1760.

53 S. R. Jadhav, P. K. Vemula, R. Kumar, S. R. Raghavan and G. John, Angew. Chem., Int. Ed., 2010, 49, 7695.

54 G. John, G. Zhu, J. Li and J. S. Dordick, Angew. Chem., Int. Ed., 2006, 45, 4772.

55 J. H. Jung, G. John, M. Masuda, K. Yoshida, S. Shinkai and T. Shimizu, Langmuir, 2001, 17, 7229.

56 L. Lu, T. M. Cocker, R. E. Bachman and R. G. Weiss, Langmuir, 2000, 16, 20.

57 Z. Xu, J. Peng, N. Yan, H. Yu, S. Zhang, K. Liu and Y. Fang, Soft Matter, 2013, 9, 1091.

58 J. Yan, J. Liu, P. Jing, C. Xu, J. Wu, D. Gao and Y. Fang, Soft Matter, 2012, 8, 11697.

59 R. Bitar, G. Agez and M. Mitov, Soft Matter, 2011, 7, 8198. 60 M. George and R. G. Weiss, Acc. Chem. Res., 2006, 39, 489. 61 D. J. Abdallah and R. G. Weiss, Adv. Mater., 2000, 12, 1237. 62 Y.-C. Lin, B. Kachar and R. G. Weiss, J. Am. Chem. Soc., 1989, 111, 5542.

63 K. Murata, M. Aoki, T. Suzuki, T. Harada, H. Kawabata, T. Komori, F. Ohseto, K. Ueda and S. Shinkai, J. Am. Chem. Soc., 1994, 116, 6664.

64 J. H. Jung, S. J. Lee, J. A. Rim, H. Lee, T. S. Bae, S. S. Lee and S. Shinkai, Chem. Mater., 2005, 17, 459.

65 T. Nishi, A. Ikeda, T. Matsuda and S. Shinkai, J. Chem. Soc., Chem. Commun., 1991, 339. 
66 K. Murata, M. Aoki, T. Nishi, A. Ikeda and S. Shinkai, J. Chem. Soc., Chem. Commun., 1991, 1715.

67 S. Shinkai, T. Nishi, A. Ikeda, T. Mutsuda, K. Shimamoto and O. Manabe, J. Chem. Soc., Chem. Commun., 1990, 303.

68 J. H. Jung, J. A. Rim, E. J. Cho, S. J. Lee, Y. Jeong, N. Kameda, M. Masudae and T. Shimizu, Tetrahedron, 2007, 63, 7449.

69 Z. Qi, P. Malo de Molina, W. Jiang, Q. Wang, K. Nowosinski, A. Schulz, M. Gradzielski and C. A. Schalley, Chem. Sci., 2012, 3, 2073.

70 S. Park, M.-H. Ryu, T. J. Shin and B.-K. Cho, Soft Matter, 2014, 10, 5804.

71 T. Kato, T. Yasuda, Y. Kamikawa and M. Yoshio, Chem. Commun., 2009, 729.

72 F. Vera, J. L. Serrano and T. Sierra, Chem. Soc. Rev., 2009, 38, 781.

73 C. Tschierske, J. Mater. Chem., 1998, 8, 1485.

74 A. M. Giroud-Godquin and P. M. Maitlis, Angew. Chem., Int. Ed., 1991, 30, 375.

75 S. Moyano, J. Barberá, B. E. Diosdado, J. L. Serrano, A. Elduque and R. Giménez, J. Mater. Chem. C, 2013, 1, 3119.

76 F. Camerel, L. Bonardi, M. Schmutz and R. Ziessel, J. Am. Chem. Soc., 2006, 128, 4548.

77 F. Camerel, L. Bonardi, G. Ulrich, L. Charbonnière, B. Donnio, C. Bourgogne, D. Guillon, P. Retailleau and R. Ziessel, Chem. Mater., 2006, 18, 5009.

78 F. Camerel, R. Ziessel, B. Donnio, C. Bourgogne, D. Guillon, M. Schmutz, C. Iacovita and J.-P. Bucher, Angew. Chem., Int. Ed., 2007, 46, 2659.

79 R. Ziessel, F. Camerel and B. Donnio, Chem. Rec., 2009, 9, 1.

80 F. Camerel, R. Ziessel, B. Donnio and D. Guillon, New J. Chem., 2006, 30, 135.

81 X. Yang, G. Zhang and D. Zhang, J. Mater. Chem., 2012, 22, 38.

82 V. Percec, D. Tomazos, J. Heck, H. Blackwell and G. Ungar, J. Chem. Soc., Perkin Trans. 2, 1994, 31.

83 V. Percec, G. Johannson, J. Heck, G. Ungar and S. V. Batty, J. Chem. Soc., Perkin Trans. 1, 1993, 1411.

84 T. Hatano and T. Kato, Chem. Commun., 2006, 1277.

85 S. Kohmoto, E. Mori and K. Kishikawa, J. Am. Chem. Soc., 2007, 129, 13364.

86 A. Bajaj, P. Kondaiah and S. Bhattacharya, Bioconjugate Chem., 2007, 18, 1537.

87 S. Bhattacharya and A. Bajaj, J. Phys. Chem. B, 2007, 111, 2463.

88 S. Bhattacharya and P. V. Dileep, Bioconjugate Chem., 2004, 15, 508.
89 S. Bhattacharya and P. V. Dileep, J. Phys. Chem. B, 2003, 107, 3719.

90 S. Bhattacharya and Y. Krishnan-Ghosh, Mol. Cryst. Liq. Cryst., 2002, 381, 33.

91 C. Danumah, R. L. Beingessner, A. Haque, F. Ban, J. P. Richards, A. Kovalenko and H. Fenniri, Langmuir, 2009, 25, 11857.

92 S. Datta, S. K. Samanta and S. Bhattacharya, Chem.-Eur. J., 2013, 19, 11364.

93 A. Barbatu, I.-C. Stancu, R.-A. Mitran and S. Tomas, Sci. Bull. - Univ. "Politeh." Bucharest, Ser. B, 2011, 73, 135.

94 J. Peng, K. Liu, J. Liu, Q. Zhang, X. Feng and Y. Fang, Langmuir, 2008, 24, 2992.

95 C. Wang, D. Zhang and D. Zhu, Langmuir, 2007, 23, 1478.

96 A. Friggeri, C. van der Pol, K. J. C. van Bommel, A. Heeres, M. C. A. Stuart, B. L. Feringa and J. van Esch, Chem.-Eur. J., 2005, 11, 5353.

97 A. R. Hirst, D. K. Smith, M. C. Feiters and H. P. M. Geurts, Chem.-Eur. J., 2004, 10, 5901.

98 N. Gimeno, J. Barberá, J. L. Serrano and M. B. Ros, Chem. Mater., 2009, 21, 4620.

99 C. W. Yang, T. H. Hsia, C. C. Chen, C. K. Lai and R. S. Liu, Org. Lett., 2008, 10, 4069.

100 N. Steinke, W. Frey, A. Baro, S. Laschat, C. Drees, M. Nimtz, C. Hägele and F. Giesselmann, Chem.-Eur. J., 2006, 12, 1026.

101 C.-C. Huzum, I. Carlescu, G. Lisa and D. Scutaru, J. Serb. Chem. Soc., 2013, 78, 669.

102 L. Y. Park and J. M. Rowe, Chem. Mater., 1998, 10, 1069.

103 H. Maeda, Y. Terashima, Y. Haketa, A. Asano, Y. Honsho, S. Seki, M. Shimizu, H. Mukai and K. Ohta, Chem. Commun., 2010, 46, 4559.

104 S. H. Seo, J. H. Park and J. Y. Chang, Langmuir, 2009, 25, 8439.

105 A. I. Norman, Y. Fei, D. L. Ho and N. C. Greer, Macromolecules, 2007, 40, 2559.

106 R. Yang, X. R. Yang and D. F. Evans, J. Phys. Chem., 1990, 94, 6123.

107 T. Ohtake, M. Ogasawara, K. Ito-Akita, N. Nishima, S. Ujiie, H. Ohno and T. Kato, Chem. Mater., 2000, 12, 782.

108 D. Vollhardt, F. Liu and R. Rudert, ChemPhysChem, 2005, 6, 1246.

109 F. H. Beijer, H. Kooijman, A. L. Spek, R. P. Sijbesma and E. W. Meijer, Angew. Chem., Int. Ed., 1998, 37, 75.

110 F. H. Beijer, R. P. Sijbesma, H. Kooijman, A. L. Spek and E. W. Meijer, J. Am. Chem. Soc., 1998, 120, 6761. 